requires attention, and what will now happen as a result of it, thus crystallising and confirming the outcomes.

Our experience is that participants find that this approach leads to their developing a learner centred rather than a teacher centred approach to their training. ${ }^{7}$ As a result they see how important it is for trainees to define their own learning objectives and that the trainer's task is to facilitate learning rather than directly to teach people what he or she thinks they ought to know. Although the scheme is unusual and quite unlike their previous experience of medical education, participants find it surprisingly unthreatening and learn a great deal about different ways of teaching. They also report new insights into their own consulting skills and often suggest that patients should play a greater part in diagnosis and management. They find, too, that their knowledge has increased despite not a single lecture having been given. Most speak of seeing the value of being open and constructively critical with their colleagues and of being helped by their peers to recognise the strengths and acknowledge the weaknesses in their professional practice.

In this approach the criteria for evaluating practice, the learning objectives, and the means for achieving change all emerge during the process - they are not defined beforehand or imposed on the participants in the course. And as they have a sense of ownership for these end points they feel more positive about their implementation. Next - and this is very important - the self assessment process provides a sound foundation for more conventional audits. By going through it participants report being more able to declare misgivings about their own consultations and to discuss with their peers general issues of clinical practice.
The essence of this approach is a reflection on actual practice $^{1011}$ - unlike much medical audit, which often reviews only abstractions of practice. Moreover, it can be generalised and adopted for other parts of medicine. It is clear too that each step in the process depends on the successful resolution of the previous one. Audit should proceed from the particular to the general and from concrete personal experience to abstract collective responsibility, but people need some means for doing so.

Those who advocate audit through peer review may claim that self assessment is implicit in their approach, but this is often not so. Introducing people to a simple procedure for self assessment such as the one described above, however, can make audit truly educative.

COLIN COLES

Senior Lecturer in Medical Education,

Faculty of Medicine,

University of Southampton,

General Hospital,

Southampton SO9 4XY

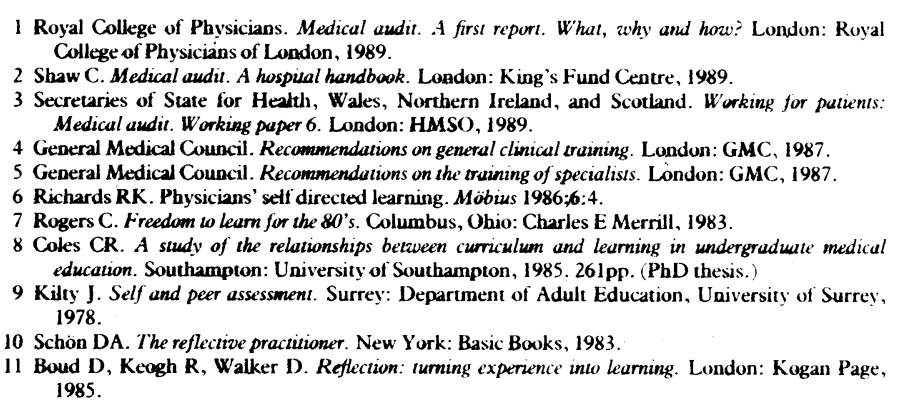

\title{
Immunisation: causes of failure and strategies and tactics for success
}

\section{Strong professional commitment is the key}

Immunisation of children is one of the most cost effective activities in health care. Impressive benefit to cost ratios have been shown in the United States for measles (12:1), rubella $(8: 1)$, and whooping cough $(11: 1) .^{12}$ Measles vaccine is also cost effective in Britain, ${ }^{3}$ and there is no reason to believe that similar benefits would not also apply for whooping cough. In Britain protection against polio, diphtheria, and tetanus has made all three rare, though a few cases still occur among the unprotected. ${ }^{+5}$ Cost-benefit ratios for these rare diseases are harder to calculate, but it would be unacceptable to stop immunisation as epidemics would inevitably return after importation of infection from abroad, and the costs can be carried by the more economic parts of the programme.

The World Health Organisation has set a target for the year 2000 for the protection of all children by immunisation; it argues that a decision to withhold immunisation should be taken only after serious consideration of the potential consequences for the individual child and the community. ${ }^{6}$ For countries in Europe a target uptake has been set of $\mathbf{9 0 \%}$ by 1990 for the primary immunisation series. ${ }^{7}$ Britain's performance is worse than most industrialised nations and even some developing countries (figure): only a handful of

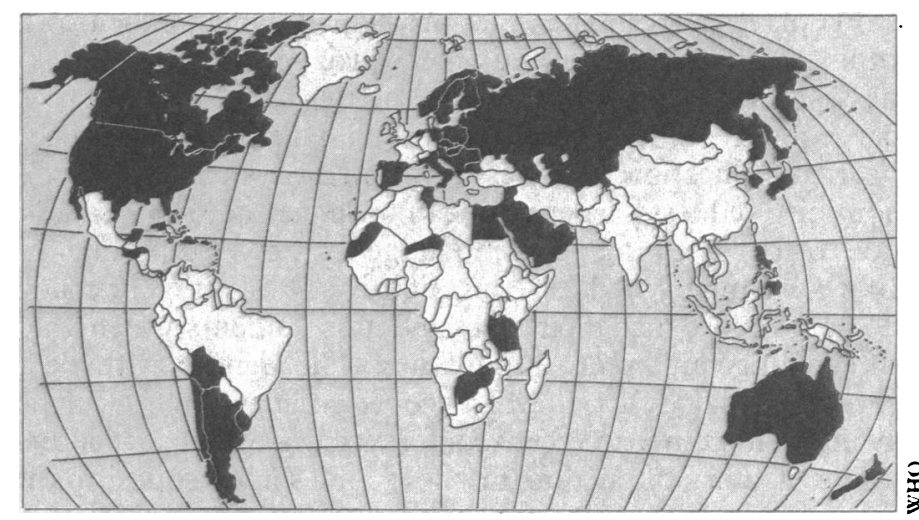

Countries with better measles completion percentages than Britain, 1987

health districts have achieved the $90 \%$ target for measles, and no district has reached $90 \%$ coverage for diphtheria, pertussis, and tetanus immunisation.

And yet there is good evidence that effectiveand enthusiastic services will achieve a good uptake even in the face of socioeconomic deprivation and parental uncertainty. ${ }^{8}$ The 
first, crucial step is for the professionals to become organised and committed to immunisation. This article reviews the obstacles to achieving a good uptake and makes some practical suggestions for improving performance.

\section{Causes of failure}

Immunisation has a low priority. In many districts community health services have lost ground to the hospital sector in terms of resources. In the community itself child health has a lower priority for growth than services for the elderly and mentally ill. Other issues-for example, nonaccidental injury - may demand attention at the expense of immunisation services, which can be divorced from the main child health surveillance programme. ${ }^{4}$

The risk is perceived to be low. Four of the preventable diseases (polio, tuberculosis, diphtheria, and tetanus) are so rare that some parents have not heard of them; many more believe that they have been eradicated. ${ }^{10}$ Both professionals and parents have the mistaken impression that measles offers little threat to children" ${ }^{\prime \prime}$ this is less true for pertussis after its recrudescence. ${ }^{12}$

Immunisation is seen as a negative activity. Repeated attention in the media to alleged vaccine damage has resulted in parents being highly aware of the possibility of adverse reactions. ${ }^{13}$ Professionals may fear that they could be held responsible. These fears, combined with the low perceived risk, have changed the attitudes of both parents and professionals to one of low commitment to immunisation. A few parents deliberately avoid protection. Some community staff feel that immunisation should not be part of the nursing process, particularly where training and medical support are inadequate.

Contraindications are a convenient way out for both parents and professionals who may wish to avoid immunisation, particularly against pertussis, because of fear of severe adverse reactions. This is often achieved by one or both parties extending the few recognised contraindications, so seeming to avoid immunisation legitimately. For example, the unsubstantiated warning about immunising "undeveloped" babies in one manufacturer's datasheet was generalised in many parts of Britain into a mythical contraindication that babies should not be protected until they had reached an arbitrary weight. Such myths are legion and are sincerely believed by professionals, who may be difficult to convince otherwise. ${ }^{14}$ Parents learn the myths and are made more insecure by receiving conflicting advice. ${ }^{15}$ When there is professional disagreement they find avoiding immunisation to be the more acceptable option.

\section{Written guidance}

Many health professionals would benefit from training and practical written guidance. Too often, children are denied protection through uncertainty about the action to take in specific circumstances. Nursing (and medical) education on immunisation often consists of lectures to large audiences during basic training, and practical issues are rarely dealt with. Nurses are usually trained by "sitting with Nellie," a method particularly effective in perpetuating myths and bad practice. Immunisation is not specifically included in the training of general practitioners and the other professionals concerned.

The authoritative Department of Health memorandum Immunisation Against Infectious Disease is comprehensiveand the 1988 edition addresses the principal "myths"- but it is not of much practical use in busy clinics and does not deal with all the problems that can arise. ${ }^{16}$ Staff working in clinics may be relying on collections of local and Department of Health circulars and manufacturers' product inserts - which may add to the confusion by being at variance with the memorandum. ${ }^{17}$

Anxiety about vaccine damage has often led to all the emphasis being on the procedures to be followed, on training and indemnity for the nurse, and on acceptable parental consent. The end result may be that procedures are cast iron legally but operationally impracticable.

The health professionals who may be approached for advice on immunisation and may need training - or at least authoritative information - are listed in the box. A handful of unenthusiastic staff may have a disproportionately large negative effect.

At present the responsibility for immunisation is divided between general practice and community services. Some practices perform well, achieving uptakes well above their district norms. ${ }^{81 \times 19}$ General practitioners are under no obligation to immunise, however, and community health services may have to fill the gap. Information transfer between the two is usually poor, and children often fall in between. ${ }^{20}$

The abolition of the medical officer of health in 1974 left uncertainty about who held ultimate responsibility for immunisation in an authority: Was it specialists in community medicine (child health), community paediatricians, or the district medical officer? Undoubtedly, this uncertainty was one of the reasons for the lack of a clear medical response to the pertussis vaccine scare that occurred the same year. ${ }^{21} \mathrm{~A}$ directive encouraging each authority to identify a person with overall responsibility was circulated in 1986 , but no additional resources or statutory powers were allocated for carrying out this task. The recent review of public health in England does not consider the question. ${ }^{22}$

In the face of inflexible and unenthusiastic services even willing families may find difficulties in protecting their children. Opportunistic immunisation (immunising when families present at non-scheduled times or offering immunisation when a child is seen for another reason) may be highly effective, but it is hard to put into practice. For example, the practice may have a policy that only doctors give injections or that they have to be on the premises; these rulings are not only expensive ${ }^{23}$ but also unnecessary. ${ }^{2+}$ When nurses immunise usually only a few do so, and others may be reluctant to step in when gaps occur-" The immunisation lady's ill, come back next week." Parents receive the message that the professionals are happier not immunising.

The first generation of computerised child health systems were unsatisfactory. They were based on central batch processing of information, and their turnround of information was slow, resulting in delays and inaccuracies. ${ }^{25}$ Remote data capture and interrogation were not usually possible, so that a nurse or doctor could not readily check or update the immunisation state of an individual child. Individual performance figures for immunisation by general practitioners, health visitors, and clinical medical officers can be obtained from the nationally available NHS child health system, ${ }^{26}$ but this information to service providers is not routinely fed back in most districts. ${ }^{27}$ These deficiencies have resulted in some general practitioners opting not to participate in district computer schemes.

\section{Strategies for improvement}

To effect an improvement in uptake of immunisation every district should, first of all, have a policy. The sheer numbers 
and diversity of staff (box) and their activities make it essential that the immunisation policy should be written before a concerted programme is mounted throughout the district. This should have aims and targets that detail activities and specify responsibilities. The nominated immunisation coordinator should have responsibility for developing the policy for a district. There should be a single responsible medical person with the right experience; usually this will be a specialist in community medicine or a consultant community paediatrician. He or she should convene a vaccination and immunisation committee to cover all the relevant professions, including general practice.

Immunisation uptake should be a key performance indicator audited by individual clinics, health visitors, and general practitioners. Any unit not achieving good results is arguably either ineffective or has incorrect priorities. ${ }^{9}$ District immunisation rates might be more widely publicised by agencies such as the Office of Population Censuses and Surveys. Regular feedback of individual performance is also required at district level. Some districts distribute league tables: an example is shown in the table.

Percentage of children born in 1985 immunised in Wandsworth Health Authority (ranking in parentheses)

\begin{tabular}{lccl}
\hline & Third diphtheria & Third pertussis & Measles \\
\hline Clinics: & & & \\
Balham & $81(8=)$ & $74(5)$ & $73(6=)$ \\
Bridge Lane & $89(2)$ & $77(3)$ & $78(4)$ \\
Brocklebank & $72(15)$ & $57(16)$ & $59(17)$ \\
Chatham Hall & $75(13)$ & $63(12)$ & $66(11)$ \\
Doddington & $85(5=)$ & $75(4)$ & $76(5)$ \\
Fairfield & $70(16)$ & $58(15)$ & $60(15=)$ \\
John Milton & $65(17)$ & $55(17)$ & $55(18)$ \\
Lola Jones & $73(14)$ & $62(13)$ & $61(14)$ \\
St Christopher & $76(12)$ & $60(14)$ & $67(10)$ \\
Southfields & $86(4)$ & $78(2)$ & $87(1)$ \\
Stormont & $81(8=)$ & $72(6=)$ & $63(12=)$ \\
Tooting & $79(11)$ & $68(8=)$ & $66(9)$ \\
General practices: & & & \\
Balham Park & $64(18)$ & $55(18)$ & $73(6=)$ \\
Barmouth Road & $94(1)$ & $81(1)$ & $70(8)$ \\
Brocklebank & $80(10)$ & $66(11)$ & $63(12=)$ \\
Kambala & $88(3)$ & $72(6=)$ & $86(2)$ \\
Queenstown & $85(5=)$ & $67(10)$ & $60(15=)$ \\
Winstanley & $82(7)$ & $68(8=)$ & $83(3)$ \\
District average & 76 & 66 & 66 \\
\hline
\end{tabular}

If there are too many targets the audit may be less effective. Measles is the best measure during the preschool years, as higher uptake is needed ${ }^{28}$ and can be achieved by professional initiatives. ${ }^{29}$ Measles also acts as a "sweeper" for the preceding "triples" and polio - if a child has missed the third dose this can be given simultaneously with measles as part of the measles, mumps, and rubella vaccination.

Immunisation should be seen as a nursing activity. The current consensus is that an immunisation course should be prescribed by a doctor, and this can conveniently be done at the six week check. Thereafter there is no legal or medical bar to immunisation being carried out by appropriately trained nurses. In Nottingham training has been established for immunisation as an extended nursing role. ${ }^{30} \mathrm{~A}$ doctor need not be present, permitting nurses to immunise in the home and isolated clinics. ${ }^{2+} \mathrm{A}$ convenient clinic arrangement is a doctor and nurse operating simultaneously, with the doctor doing non-immunisation work but being available for consultation. Immunisation by nurses allows integration of child health surveillance with immunisation and leads to an improved uptake and a more efficient use of staff. ${ }^{2+}$

Immunisation should be an integral part of any child health

\section{Professionals concerned with immunisation}

Clinic nurses

Health visitors

School nurses

Practice nurses

Nurse managers and trainers

Clinical medical officers

Community physicians

\author{
General practitioners \\ GP trainees \\ Paediatricians \\ Community unit \\ administrators \\ Health educators \\ Pharmacists
}

surveillance programme, promoted at all structured reviews: the health visitor's birth visit (when consent can be signed), the medical six week check (medical prescription), preschool reviews by health visitors or doctors, and the medical examination at school entry. Surveillance programmes provide the continuity needed to achieve high immunisation uptake in successive cohorts of children. ${ }^{31}$ Developmental assessments also provide chances for opportunistic immunisation.

\section{Tactics}

All primary care professionals need to be convinced of the importance of immunisation. Simple information and counselling skills are required by many groups; those actually immunising should also undergo supervised practice leading to accreditation. The training package developed in Nottingham for nurses has been adapted for other groups, such as general practitioner trainees. ${ }^{30}$ It is run by a nurse manager or trainer and covers basic knowledge of the diseases and immunisation, counselling skills, real and mythical contraindications, vaccine handling, and documentation. Management of anaphylaxis is also included. Training has to be repeated: updating is essential to maintain standards and enthusiasm and to introduce new vaccines. A nurse trainer requires medical support outside the training session.

The immunisation queries that arise in day to day practice may have been covered in training, but staff will not retain every answer. Clearly written statements are helpful, particularly because of the anxieties raised by immunisation. Both doctors and nurses in Nottingham use an A5 sized practical guide that deals with most of the queries that arise in practice and counters the commoner myths. Other districts have adapted this or produced shorter cards that detail the major myths and contraindications. The British Paediatric Association has produced an enlarged national version that also advises on the commoner infectious diseases of children. ${ }^{32}$ These guides do not replace the memorandum from the Department of Health, the final authority with which local guides must be compatible. ${ }^{16}$ Careful attention must be paid to wording, and guides should be released only after extensive local consultation and with the authority of the local vaccination and immunisation committee.

In isolation, public vaccination campaigns are of limited value. Although they will increase uptake, ${ }^{33}$ unless the effort is sustained this may return to previous levels. ${ }^{3+35}$ If professionals are not concerned in the planning, campaigns may expose ill prepared services. One solution is to have an immunisation promotion group running small campaigns at regular intervals, keeping immunisation on the health agenda. An amalgamation of health education staff and practising staff works well, with turnover in the group membership bringing in fresh ideas. The group will find from 
experience the publicity methods that work locally (for example, the letter from Roald Dahl available from Sandwell Health Authority, 8 Grange Road, West Bromwich, West Midlands B70 8PD) and can assess other health education materials. A press liaison officer is essential to build up relations with the local press and television, which will eventually consult him or her before running a story on immunisation.

Authorised staff should use the media whenever necessary, either as part of a planned campaign or in response to a crisis. Being reported as "not available for comment" is a weak reply to inquiries. By rapidly responding one authority (Fife) weathered the disaster of twin cot deaths coinciding with immunisation; there was no measurable fall in uptake. In the public view doctors carry more weight than authority representatives.

Immunisation targets need to be set and audited at every level of organisation. It is unreasonable to expect individual professionals to audit their own records; the data should be available from the child health records held in the computer. Computerisation of records has been associated with an improved uptake of immunisation. ${ }^{36}$ Whether this is cause and effect is less clear, though practices that withdraw from computer systems may show a drop in performance. ${ }^{37}$ The nationally available NHS child health system is currently used by 146 of the 199 health districts in England and Wales; most other districts have comparable commercial or in house systems.

The desirable features for a computerised child health system are listed in the box. Most of these features are now available within the NHS system. With the recent release of a new statistical package ${ }^{-h}$ rapid assessment of vaccine coverage is possible, both locally and nationally. ${ }^{3 x}$ The NHS system will become fully interactive in 1990 after a technical rewrite.

The procedures for a variety of circumstances should be worked out locally by the vaccination and immunisation committee. Any new procedure needs to be thought through and if possible run first as a trial. If the procedure is sufficiently important all appropriate committees should be asked to comment and authorise. Only then should legal advice be sought if it is considered to be essential. But written

\section{Requirements for computerised child health systems}

- Regular supply of uptake figures and default lists for all levels of the organisation-general practitioner, health visitor, clinic, school, school nurse, sector, district

- Linkage with birth notifications, hospital, and family practitioner systems

- A complete register of all children resident in a health district, linked to other child registers - for example, special needs

- Replacement rather than duplication of manual records

- On line updating with facility for this to be done by peripheral terminals

- Capacity to incorporate new procedures swiftly

- Rapid turnround of data

- Compatibility with surrounding authorities to allow for electronic transfer of information

- Facility for local scheduling of appointments guidance cannot cover every eventuality - immediate advice on whether to immunise a child is needed from time to time and information on an individual child's previous injections is often required. It is useful to have a single telephone line staffed by a skilled clerk who can deal with administrative inquiries and refer clinical calls to locally agreed experts on immunisation. It may be necessary to have a member of medical staff on call outside of working hours to deal with emergencies. These are rare, and usually concern a child who is admitted to hospital either after immunisation or with a serious infectious disease.

Information about immunisation needs to be disseminated to professionals between new editions of the Department of Health memorandum. To avoid the proliferation of circulars a single clear channel is needed. Fife has a regular newsletter combining information on immunisation with details of . infectious diseases, and Nottingham uses a section of a community pharmacy newsletter. Distribution to general practitioners and practice nurses through family practitioner committees is essential.

All immunisation information for parents needs to be reviewed occasionally. Health education materials usually give a positive impression but can contain errors. Routine immunisation forms are more often at fault in giving a negative impression.

\section{Special issues}

Some districts have clinics for "grey areas," those in which there is professional uncertainty over whether to recommend immunisation. ${ }^{39}$ There are reservations concerning this practice. Patients who are referred are usually immunised and the clinics are able to carry out important research and show leadership ${ }^{39}$; but this system allows doctors to pass the buck. Many of the referrals are straightforward cases of what are erroneously seen to be contraindications; though the clinics write to the referring doctor, such unjustified referrals may continue.

Some neonatal services state in discharge summaries whether immunisation with pertussis is recommended when the perinatal course has been stormy. This practice is helpful as the children are often being followed up in outpatient clinics when immunisation is due to start and the parents are still influenced by the paediatrician's opinion. When a baby has been in hospital for more than three months many neonatal units start immunisation before discharge (although not for polio because of possible circulation of the virus inside the unit). This reinforces the message that no allowance need be made for prematurity. ${ }^{+0}$

Attendance at the accident and emergency department or admission to hospital provides an opportunity for immunisation. ${ }^{+1}$ Though this is a routine practice in most developing countries, difficulties arise in Britain as information on a child's immunisation state is not readily accessible. When computer systems allow remote interrogation there is a strong case for having a terminal in each district hospital. Hospital immunisation may then be incorporated into the discharge procedure.

A district in which nurses have been trained to immunise without a doctor being present can mount a domiciliary immunisation service. ${ }^{+2}$ Such schemes are expensive, but they may be essential in rural areas with isolated families who do not possess transport; for special groups (particularly "travellers"); and in emergencies (for example, outbreaks of polio and diphtheria), when mass protection is needed promptly. A first immunisation given as part of a home visit may lead non-attenders to attend the clinic for further immunisations. 
The medical examination at school entry provides a further opportunity to identify and immunise children whose immunisations are not up to date. Procedures for identifying and excluding unvaccinated children from school during outbreaks of a disease should be agreed between health and education authorities. This task is simple when school health records have been computerised.

The uptake of immunisation is better among ethnic minority children born in Britain than in indigenous inner city populations, ${ }^{+3+}$ but this may not be the case for first generation immigrants, in whom lack of knowledge is compounded by language difficulties. ${ }^{+5}$ These families are at greater risk because of possible exposure to illnesses such as polio, diphtheria, and tuberculosis when visiting relatives abroad. There are organisational difficulties in determining what schedules to apply to older children and adults who have not been immunised.

There is a case for mandatory immunisation before school entry. ${ }^{+6} \mathrm{Good}$ uptake of immunisation is possible without this, however, and laws that would specify immunisation as a condition for school entry are not without their drawback. ${ }^{9}$ Legislation could be enforced only when uptake levels are high and when it is considered socially unacceptable not to immunise a child.

1 White CC, Koplan JP, Orenstein WA. Benefits, risks and costs of immunisation for measles, mumps and rubella. Am f Public Health 1985;75:739-44.

2 Hinman AR, Koplan JP. Pertussis and pertussis vaccine. Reanalysis of benefits, risks and costs. FAMA 1984:251:3109-13.

3 McDonall WWM, Tohani VK. Measles in the Southern Health Board-implications for resources. BrMed F 1984;289:293-6.

4 Begg NT, Chamberlain R, Roebuck M. Paralytic poliomyelitis in England and Wales 1970-84. Epidemiol Infect 1987;99:97-106

5 Bowler ICJ, Mandal BK, Schlecht B, Riordan T. Diphtheria-the continuing hazard. Arch Dis Child 1988;63:194-210.

6 World Health Organisation. Indications and contraindications for vaccines used in the EPI. World Health Organization Weekly Epidemiology Record 1984;3:13-5.

7 Begg NT, Noah ND. Immunisation targets in Europe and Britain. Br Med f 1985;291:1370-1.

8 James J, Clark C, Rossdale $M$. Improving health care dehivery in an inner-city well baby clinic. Arch Dis Child 1986;61:630.

9 Anonymous. Immunisation policy: recipes for success [Editorial]. Lancet 1987;ii:78-80.

10 Harding $\mathrm{CH}$, O'Looney BA. Perceptions and beliefs about nine diseases. Public Health 1984;98:284-93

11 Blair S, Shave N, McKay J. Measles matters but do parents know? Br Med f 1985;290:623-4.

12 Health Education Council. MORI opinion poll on attitudes to whooping cough. London: Health Education Council, 1985.

13 Harding CH. Immunization as depicted by the British national press. Community Med 1985;7: $87-98$.

14 Hull D. Why children are not immunised. $f R$ Coll Physicians Lond 1987;21:28-31.

15 Pugh EJ, Hawker R. Measles immunization: professional knowledge and intention to vaccinate. Community Med 1986;8:340-8.

16 Department of Health and Social Security. Immunisution against infectious disease. London: HMSO, 1988.

17 Nicoll A, Hull D. Immunisation misinformation. Lancet 1984;ii: 1215-6.

18 Alberman E, Watson F, Mitchell P, Day S. The development of performance and cost indicators for pre-school immunisation. Arch Dis Child 1986;61:251-6.

19 Burney PGJ, Cook DG. Mothers' intentions and immunisation of infants. $f$ R Coll Gen Prac 1983;33:229-32.

20 Lakhani ADH, Morris RW, Morgan M, Dale C, Vaile MSB. Measles immunisation: feasibility of a 90\% target uptake. Arch Dis Child 1987;62:1209-14.

21 Committer on Safety of Medicines and Joint Committee on Vaccination and Immunisation. Whooping cough. London: HMSO, 1981.

22 Committee of Inquiry into the Future Development of the Public Health Function. Public health in England. London: HMSO. 1988. (Acheson report)

23 Macfarlane JA. Whose job is it to give immunisation? Journal of Maternal and Child Health 1984;9:302-5.

\section{Conclusions}

Immunisation coverage, though improving, is still inadequate in Britain. Elimination of the diseases preventable through vaccination will require at least $90 \%$ of children to be immunised. This can be achieved only by enthusiastic professionals committed to immunisation who are backed up by an efficient, flexible organisation. Our recommendations are intended to serve as a checklist for coordinators of immunisation programmes. They do not necessarily apply in every district, and local conditions will determine the best strategies.

Wellcome Lecturer,

A NICOLL

Department of Epidemiological and Population Sciences,

London School of Hygiene and Tropical Medicine,

London WCIE 7HT

Lecturer in Community Child Health,

D ELLIMAN

St George's Hospital Medical School,

London SW 17 0RE

Consultant Epidemiologist,

N T BEGG

PHLS Communicable Disease Surveillance Centre,

London NW9 5EQ

24 Jefferson N, Sleight G, Macfarlane A. Immunisation of children by a nurse without a doctor present. Br.Med f 1987;294:423-4.

25 Hopton C, Davison J, Fearn H, Beal JA, Hedley AJ. Are computers used appropriately in preventive child health? Med Inf 1982;16:532-8.

26 Child Health Computing Committee. The child health system-a stutistical guide Cardiff: Welsh Health Common Services Authority, 1987.

27 Begg NT, White J. A survey of pre-school immunisation programmes in England and Wales. Community Med 1988;10:344-50.

28 Campbell AGM. Measles immunisation: why have we failed? Arch Dis Child 1983:58:3-5

29 Nicoll A. Tactics for increasing vaccine acceptance without compulsion. In: Miller CL, ed. Scientific hasis of rubella vaccination strategv. London: Public Health Laboratory Service, 1987 34-6.

30 Hutchinson T, Nicoll A, Polnay L, Roden D. A training procedure for immunisation. Health Trends 1987;19:19-24.

31 While AE. Health visitor contribution to pre-school child prophylaxis. Public Health 1987;101 229-32.

32 British Paediatric Association. Manual on infections and immunization in children. Oxford: Oxford University Press, 1989.

33 Ryan RP. Measles vaccination: the 1983 Bedfordshire campaign. Health Educution fournal 1984;43:112-5.

$3+$ Carter H. Improving measles vaccine uptake. Heulth l'isitor 1985;58:287-9.

35 Bruce-Quay $M$. The Calderdale immunisation project. Health Visitor 1981;54:359-62.

36 Busser AL, Homes BS. Immunisation levels and the computer. Lancet 1978;ii:450.

37 St J Newman CP. Immunisation in childhood and computer scheme participation. Public Health 1983;97:208-13.

38 Begg NT, Gill ON, White JM. "Cover" (cover of vaccination evaluated rapidly): description of the England and Wales scheme. Public Health (in press).

39 Lingham S, Miller CL, Pateman J. Role of an immunisation advisory clinic. Br Med 1986;292:939-40

t0 Lingham S, Noah N, Hull D, Harris RJ, Isaacs D. Immunisation of preterm infants. Br Med $\mathcal{J}$ 1986;292:1183-5

41 Fulginiti VA. Incomplete immunization, hospitalization, and specialty care. An opportunity to improve the immunization status of very young children. Am $\mathcal{J}$ Dis Child 1988;142:704.

42 Jones AE. Domiciliary immunisation for pre-school child defaulters. Br Med 7 1984;289:1429-31.

43 Baker MR, Bandaranyake R. Schweiger MS. Differences in rate of uptake in immunisation among ethnic groups. Br.Med f 1984;288:1075-8.

H Bhopal RS, Samim AK. Immunization uptake of Glasgow Asian children: paradoxical benefit of communication barriers? Community Med 1988;10:215-20.

45 Morgan S, Aslam M. Dove R. Nicoll A, Stanford R. Knowledge concerning infectious diseases and immunisation amongst Asian and white parents. Health Education foumal 1987:46:177-9.

46 Noah ND. Immunisation before school entry: should there be a law? Br. Med f 1987;294:1270-1. 